\title{
Fatigue Resistance and Failure Behavior of Penetration and Non-Penetration Laser Welded Lap Joints
}

\author{
Xiangzhong Guo, Wei Liu* ${ }^{*}$, Xiqing Li, Haowen Shi and Zhikun Song
}

\begin{abstract}
Penetration and non-penetration lap laser welding is the joining method for assembling side facade panels of railway passenger cars, while their fatigue performances and the difference between them are not completely understood. In this study, the fatigue resistance and failure behavior of penetration 1.5+0.8-P and non-penetration 0.8+1.5-N laser welded lap joints prepared with $0.8 \mathrm{~mm}$ and $1.5 \mathrm{~mm}$ cold-rolled $301 \mathrm{~L}$ plates were investigated. The weld beads showed a solidification microstructure of primary ferrite with good thermal cracking resistance, and their hardness was lower than that of the plates. The 1.5+0.8-P joint exhibited better fatigue resistance to low stress amplitudes, whereas the $0.8+1.5-\mathrm{N}$ joint showed greater resistance to high stress amplitudes. The failure modes of $0.8+1.5-\mathrm{N}$ and 1.5+0.8-P joints were $1.5 \mathrm{~mm}$ and $0.8 \mathrm{~mm}$ lower lap plate fracture, respectively, and the primary cracks were initiated at welding fusion lines on the lap surface. There were long plastic ribs on the penetration plate fracture, but not on the non-penetration plate fracture. The fatigue resistance stresses in the crack initiation area of the penetration and non-penetration plates calculated based on the mean fatigue limits are $408 \mathrm{MPa}$ and $326 \mathrm{MPa}$, respectively, which can be used as reference stress for the fatigue design of the laser welded structures. The main reason for the difference in fatigue performance between the two laser welded joints was that the asymmetrical heating in the non-penetration plate thickness resulted in higher residual stress near the welding fusion line.
\end{abstract}

Keywords: Laser welded lap joint, Penetration and non-penetration, Fatigue resistance, Fracture behavior

\section{Introduction}

The cold-rolled $301 \mathrm{~L}$ plate is a metastable austenitic stainless steel containing less chromium and nickel and adding austenitizing element nitrogen, which is the main material used in the manufacturing of railway light stainless steel passenger cars $[1,2]$. Owing to the different amounts of strain-induced martensite transformed in the cold rolling process, the yield strength of cold-rolled plates ranges from $200 \mathrm{MPa}$ to $700 \mathrm{MPa}$, which determines that the welding methods used in the manufacturing of vehicles are resistance spot welding and laser welding with concentrated heat input to reduce the

\footnotetext{
*Correspondence: weiliu@bjtu.edu.cn

School of Mechanical, Electronic and Control Engineering, Beijing Jiaotong University, Beijing 100044, China
}

deterioration of the mechanical properties of cold-rolled plates caused by welding heat $[3,4]$. Penetration and nonpenetration laser welded lap joints are common joining methods in rail passenger cars, and the non-penetration laser lap welding is an assembling method for side facade panels of passenger cars, which can not only improve corrosion resistance but also provide vehicle bodies with a weld-free appearance $[5,6]$. However, unlike penetration laser welded lap joints, the fatigue fracture of nonpenetration laser welded lap joints usually occurs in the non-penetrated plate even if its nominal stress is much smaller than that of the penetration plate, which results in a large difference in fatigue performance between the two lap joints $[7,8]$.

Many studies have been conducted on the fatigue performance of laser welded lap joints. Asim et al. [9] 
Table 1 Chemical compositions and mechanical properties of the experimental 301L plates

\begin{tabular}{|c|c|c|c|c|c|c|c|c|c|c|}
\hline \multicolumn{8}{|c|}{ Chemical compositions (wt. \%) } & \multicolumn{3}{|c|}{ Mechanical properties } \\
\hline C & $\mathrm{Si}$ & $\mathrm{Mn}$ & $P$ & S & $\mathrm{Ni}$ & $\mathrm{Cr}$ & N & $\sigma_{s}(\mathrm{MPa})$ & $\sigma_{b}(\mathrm{MPa})$ & $\delta(\%)$ \\
\hline$<0.03$ & $<1.0$ & $<2.0$ & $<0.045$ & $<0.03$ & $6-8$ & $16-18$ & $<0.2$ & $>350$ & $>700$ & $>40$ \\
\hline
\end{tabular}

investigated the fatigue behavior of penetrating laser welded lap specimens made of high strength steel. The specimens failed in the upper plate at high-cycle fatigue life owing to the weld bead protrusion on the lower plate. Ono et al. [10] conducted fatigue tests on penetrating laser welded lap specimens with different plate thicknesses and found that the fatigue strength tended to increase with increasing plate thickness. Kaitanov et al. [11] investigated the fatigue strengths of steel laser welded lap joints under various welding conditions, and the result showed that the fatigue strength is dependent on the weld width. Cho et al. [12] investigated the fatigue strength of laser welded lap joints by considering of residual stresses obtained from thermo-elastic-plastic finite element analyses. Sripichai et al. [13] calculated the global and local stress intensity factor solutions for preexisting and kinked cracks to predict the fatigue lives of laser welded lap specimens. Marulo et al. [14] compared three notch stress approaches for the fatigue assessment of laser welded lap thin-walled joints made of mild and high strength steel.

However, there have been few research reports on the quantitative differences in fatigue properties between penetration and non-penetration laser welded joints. In this study, the penetration and non-penetration laser welded lap joints common to railway passenger cars were prepared using the same 301L cold-rolled plates. The fatigue resistances and failure behaviors of the two joints at low and high stress amplitudes were compared, and the causes of the different fatigue performances of the two joints were analyzed. The structural stress at the initial position of the fatigue crack in the two welded joints was calculated based on the fatigue limits to assist the fatigue design of vehicles.

\section{Experiments and Materials}

Cold-rolled $301 \mathrm{~L}$ plates with thicknesses of $1.5 \mathrm{~mm}$ and $0.8 \mathrm{~mm}$ were used to prepare the welding specimens, and the chemical compositions and mechanical properties of the experimental plates are given in Table 1. The lap plates were welded by a laser beam with a diameter of 0.5 $\mathrm{mm}$ using the laser welding parameters given in Table 2 under side-blown argon gas shielding. The specimen in Table 2 is numbered by the thickness of the upper and lower lap plates and the penetrating state.
The structure and dimensions of the machined penetration $1.5+0.8-\mathrm{P}$ and non-penetration $0.8+1.5-\mathrm{N}$ laser-welded specimens are shown in Figure 1(a), and Figure 1(b) shows two surfaces of an actual $0.8+1.5-\mathrm{N}$ specimen, where no welding vestiges and heating discoloration are visible on the outer side of the skin sheet.

The microstructures of two laser welded joints were characterized by optical microscope (OM) and scanning electron microscope (SEM), and the Vickers hardness was measured near the lap interface. Static stretching and fatigue tests were carried out on the MTS test machines. Fatigue experiments were performed at a frequency of $15 \mathrm{~Hz}$ using sinusoidal-pulse loads with constant amplitudes and a load ratio of $R=0.1$. The runout fatigue life was $N=2 \times 10^{6}$ cycles. Cross-sectional micrographs and fractographs of the fatigue failure specimens were used to investigate the starting position and expansion path of fatigue cracks. Stress simulation analysis was carried out to study the fatigue resistance stress at the starting region of the fatigue fracture.

\section{Experimental Results}

\subsection{Microstructure and Tensile Performance}

Figure 2 shows micrographs of the non-penetration $0.8+1.5-\mathrm{N}$ and penetration $1.5+0.8-\mathrm{P}$ laser welded joints; the overall views in Figures 2(a) and (b) show that the lap interface of the two welded joints fits well without intervals. The weld bead of the $1.5+0.8-\mathrm{P}$ joint is much larger than that of the $0.8+1.5-\mathrm{N}$, and their welding widths on the lap interface are $0.84 \mathrm{~mm}$ and $0.78 \mathrm{~mm}$, respectively. To characterize more clearly the microstructure of weld boundary and the heat-affected zone (HAZ), the $0.8+1.5-\mathrm{N}$ joint was deeply corroded. Figure 2 (c) shows a micrograph of the welding fusion line and HAZ, in which the weld boundary at the lap interface is well fused and

Table 2 Laser welding parameters of the penetration and nonpenetration lap joint

\begin{tabular}{lllc}
\hline Specimen & $\begin{array}{l}\text { Welding power } \\
(\mathrm{kW})\end{array}$ & $\begin{array}{l}\text { Welding speed }(\mathrm{m} / \\
\mathrm{min})\end{array}$ & $\begin{array}{l}\text { Defocus } \\
\text { distance } \\
(\mathrm{mm})\end{array}$ \\
\hline $0.8+1.5-\mathrm{N}$ & 2.5 & 2.1 & 0 \\
$1.5+0.8-\mathrm{P}$ & 2.9 & 1.5 & -1.2 \\
\hline
\end{tabular}




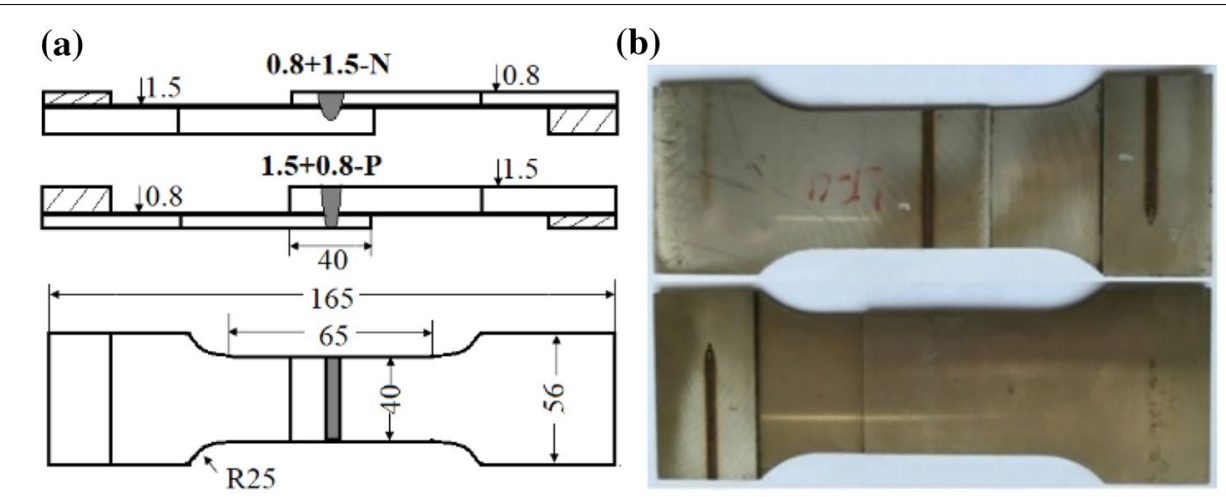

Figure 1 Structure and dimensions ( $\mathrm{mm}$ ) of the specimen: a schematic diagram of penetration 1.5+0.8-P and non-penetration 0.8+1.5-N laser welded lap joints, $\mathbf{b}$ both sides of actual $0.8+1.5-\mathrm{N}$ specimen

there are no local solidification defects. Figure $2(\mathrm{~d})$ is a micrograph of $1.5+0.8-\mathrm{F}$ weld bead whose position is shown in Figure 2(b), and the microstructure is austenite substrate and vermicular and skeleton ferrite solidified with primary ferrite, which means that the laser weld has a good thermal cracking resistance. No obvious grain growth was observed in the HAZ near the welding fusion line and convex rolling deformed grains can be seen, which indicates that the microstructure in the HAZ did not degrade significantly.

Figure 3 shows the microhardness profiles of the two laser welded joints measured near the lap interface, and a schematic diagram of the test method is shown in the hardness curve. The hardness of the weld beads is close to that of the HAZ but lower than that of the coldrolled plates. The average hardnesses of the $1.5+0.8-\mathrm{F}$ and $0.8+1.5-\mathrm{N}$ weld beads were $229 \mathrm{HV}$ and $215 \mathrm{HV}$, respectively, and the hardness of the former was slightly higher owing to its higher ferrite content. Figure 4 shows two static tensile curves and the failed $0.8+1.5-\mathrm{N}$ and $1.5+0.8-\mathrm{P}$ specimens, and the load in the ordinate was normalized by the welding length. The tensile curves of the two welded specimens are almost coincident, and due to the deformation of the $0.8 \mathrm{~mm}$ plate, the curves exhibit great ductility. The tensile shear fracture of both specimens occurred at the interfacial weld, and the maximum load of the 1.5+0.8-P specimen was higher because of its wider interfacial weld bead.

\subsection{Fatigue Resistance}

Fatigue experiments were performed on the $0.8+1.5-\mathrm{N}$ and 1.5+0.8-P specimens based on their tensile test results. The $\mathrm{S}-\mathrm{N}$ curve in the overload region was measured by single-point fatigue tests, and the fatigue limit at $2 \times 10^{6}$ cycle life was measured by lifting fatigue tests. The initial load in a single-point fatigue test was
$35 \%$ of the maximum tensile load of the specimen; the subsequent loading level was reduced by $3 \%$ to $5 \%$ of the maximum load in turn. All the loading levels were located in the linear elastic portion of the tensile shear curve. Figure 5 shows fatigue lift charts of the lifting tests for the two specimens, in which " $\mathrm{X}$ " indicates that the specimen ruptured in less than $2 \times 10^{6}$ cycles, and "O" indicates that the specimen ran out of $2 \times 10^{6}$ cycles without fracture.

The adjacent fracture and runout specimens were matched to a pair of subsamples, and the fatigue limits were calculated based on Figure 5 using the following fatigue statistical formula [15]:

$$
\begin{aligned}
& P_{r}=\left(\sum n_{i} P_{r i}\right) / N, \\
& P_{p}=P_{r}+k s,
\end{aligned}
$$

where $P_{r}$ is the mean load of $N$ pairs of subsamples, $k$ is the unilateral tolerance coefficient, $s$ is the standard deviation, and $P_{p}$ is the fatigue limit of the $p$ survival probability. The fatigue limits with a survival probability of $50 \%$ and $99.9 \%$, a confidence rate of $90 \%$, and an error rate of less than $5 \%$ are shown in Table 3, where the fatigue limits are the test loads and the normalized loads by the weld length, respectively. The fatigue limits of the non-penetration $0.8+1.5-\mathrm{N}$ specimen were much lower than those of the penetration 1.5+0.8-P specimen. In general, the mean fatigue limit $P_{50}$ (with a $50 \%$ survival rate) of lap welded joints was found to be $10 \%-20 \%$ of the static maximum tensile loads [16], and the ratios of the $0.8+1.5-\mathrm{N}$ and $1.5+0.8-\mathrm{P}$ specimens were $15 \%$ and $19 \%$, respectively. This suggests that the fatigue resistance of both the penetration and non-penetration joints is within a reasonable range. 

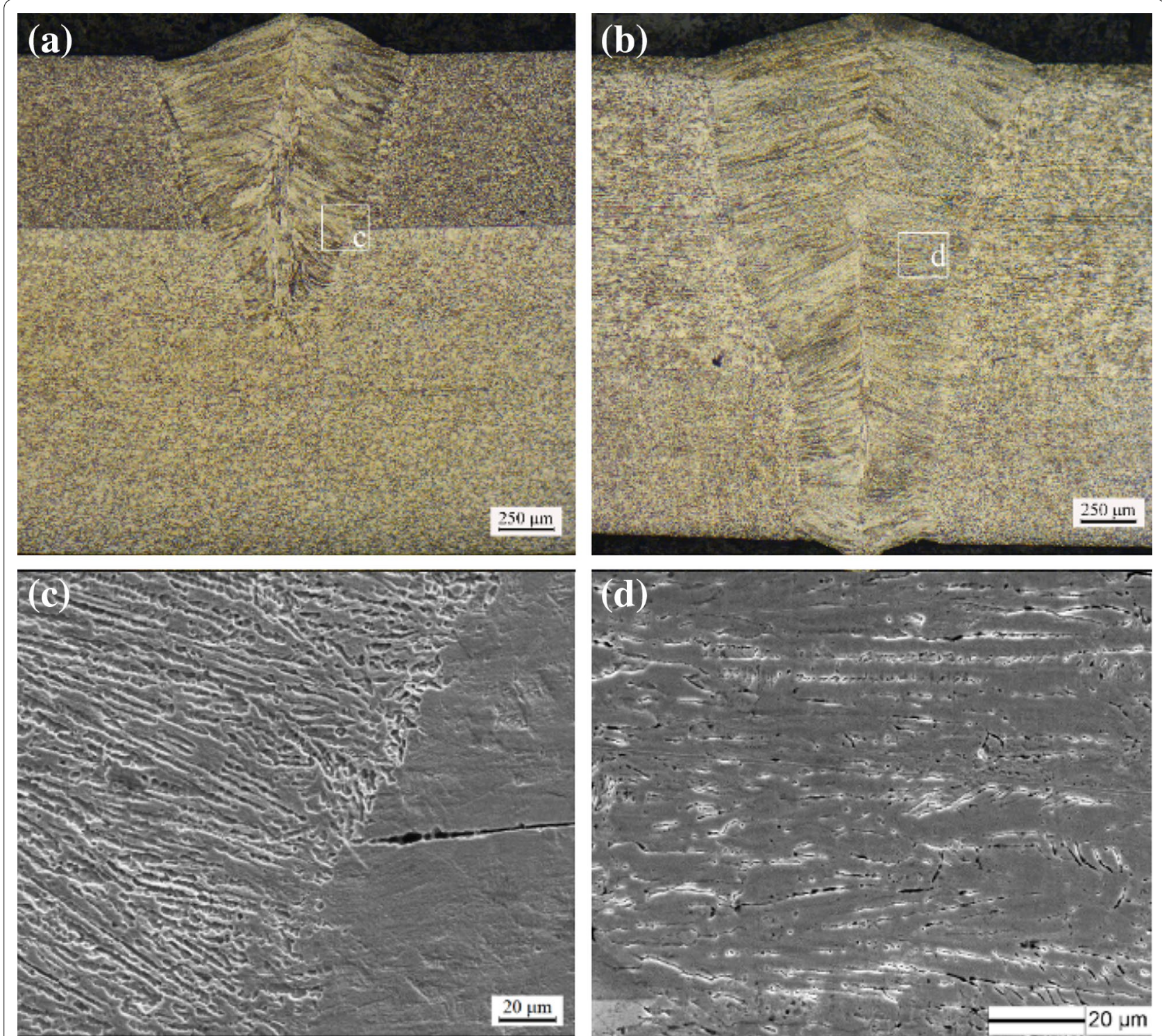

Figure 2 Micrographs of laser welded lap joints: a overall view of $0.8+1.5-\mathrm{N}$, b overall view of $1.5+0.8-\mathrm{P}, \mathbf{c}$ microstructures of welding fusion line and HAZ of $0.8+1.5-\mathrm{N}$ near lap interface, $\mathbf{d}$ microstructure of $1.5+0.8-\mathrm{P}$ weld

Figure 6 shows the S-N curves based on the results of the single-point test and lifting test, in which the runout load is the mean fatigue limit. The crossed S-N curves indicate that the penetration and non-penetration joints have different fatigue resistances to low and high stress amplitudes. The $0.8+1.5-\mathrm{N}$ joint has a slightly higher fatigue resistance to the high stress amplitudes, but a much lower resistance to the low stress amplitudes, whereas the $1.5+0.8-\mathrm{P}$ joint is the opposite. The fatigue test data in the low stress amplitudes of the $0.8+1.5-\mathrm{N}$ joint shown in Figure 5 are more discrete than those of the $1.5+0.8-\mathrm{P}$ joint.

\subsection{Fatigue Failure Behavior}

Figure 7 shows cross-sectional micrographs of the fatigue specimens that failed at low and high stress amplitudes, and double welding fusion boundaries can be found in some $0.8+1.5-\mathrm{N}$ and $1.5+0.8-\mathrm{P}$ specimens, which may be caused by the instability of the laser beam. Figure $7(\mathrm{a})$ and (b) are micrographs of $0.8+1.5-\mathrm{N}$ specimens that failed at a low stress amplitude (with $1.01 \times 10^{6}$ cycle life) and high stress amplitude (with $3.84 \times 10^{4}$ cycle life), whose primary crack initiated at the welding fusion boundary of the non-penetrating $1.5 \mathrm{~mm}$ plate lap interface and extended through the plate thickness, 


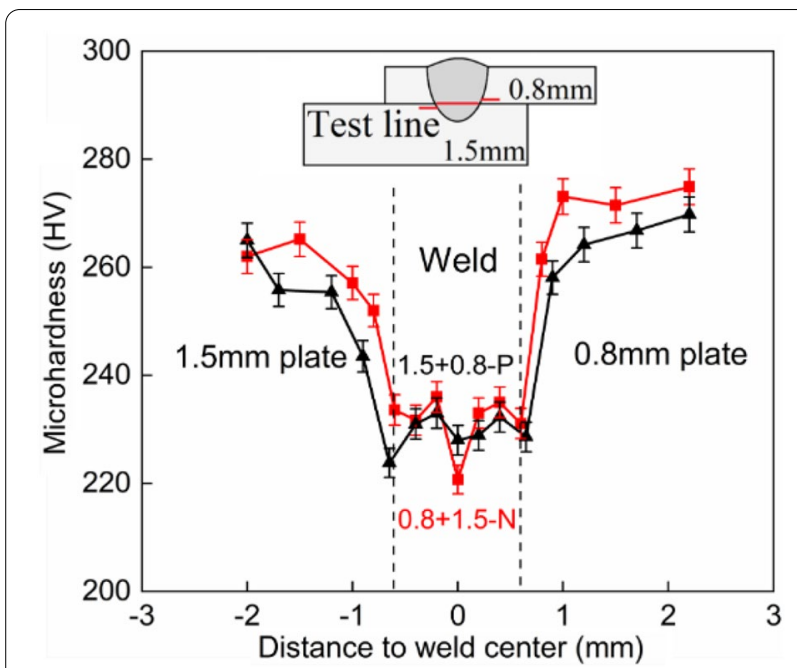

Figure 3 Microhardness profiles of two laser welded joints

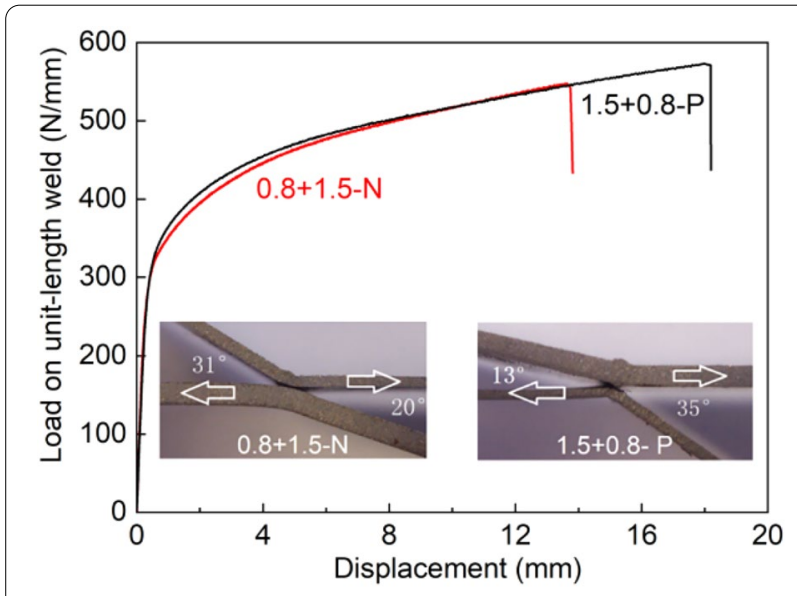

Figure 4 Tensile shear curves of two laser welded joints

as shown by the arrow. There is a secondary crack in the penetrating $0.8 \mathrm{~mm}$ plate of the high stress amplitude failure joint, whereas there is no secondary crack in the low stress amplitude failure joint. Figures $7(\mathrm{c})$ and (d) are micrographs of 1.5+0.8-P specimens that failed at a low stress amplitude (with $1.68 \times 10^{6}$ cycle life) and high stress amplitude (with $1.51 \times 10^{4}$ cycle life), whose primary crack also started at the welding fusion boundary of the $0.8 \mathrm{~mm}$ lower plate lap interface and extended through the plate thickness, and no secondary cracks were found in the two specimens. There was a significant plastic deformation in the $0.8 \mathrm{~mm}$ fractured plate of the high stress amplitude failure specimen.

Figure 8 shows fatigue fractographs of the non-penetration $1.5 \mathrm{~mm}$ plate in a $0.8+1.5-\mathrm{N}$ specimen fractured at a low stress amplitude (with $1.01 \times 10^{6}$ cycle life), and the

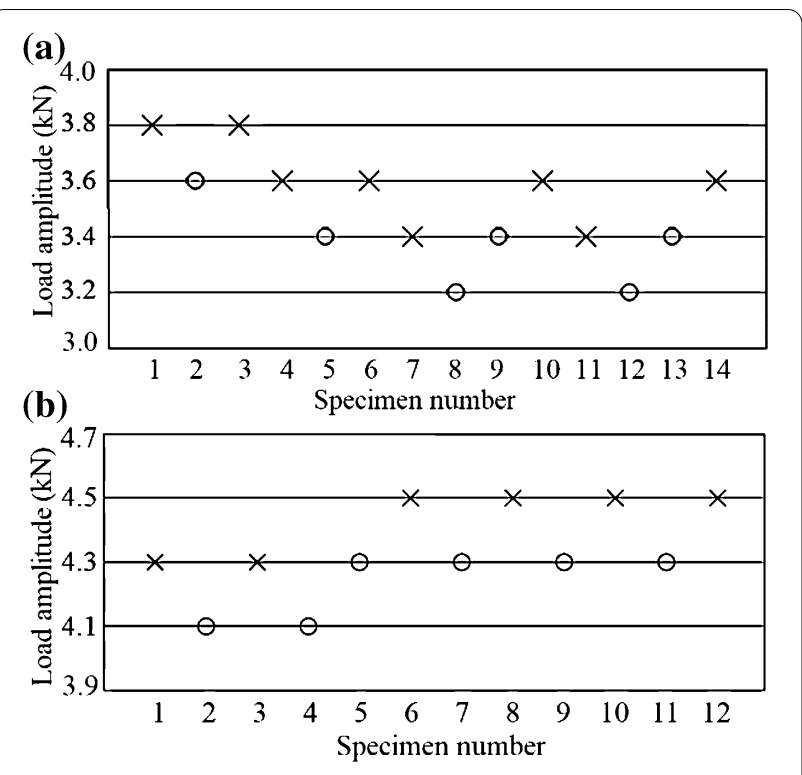

Figure 5 Fatigue lift charts of $\mathbf{a} 0.8+1.5-\mathrm{N}, \mathbf{b} 1.5+0.8-\mathrm{P}$ specimens

crack in each fractograph propagated from the bottom to

Table 3 Fatigue limits with 50\% and 99.9\% survival rates, presented in load and normalized load by weld length

\begin{tabular}{|c|c|c|c|c|}
\hline \multirow[t]{2}{*}{ Specimen } & \multicolumn{2}{|c|}{ Fatigue limit $P_{50}$} & \multicolumn{2}{|c|}{ Fatigue limit $P_{99.9}$} \\
\hline & Load (kN) & $\begin{array}{l}\text { Normalized } \\
\text { load }(\mathrm{N} / \mathrm{mm})\end{array}$ & Load (kN) & $\begin{array}{l}\text { Normalized } \\
\text { load (N/ } \\
\mathrm{mm} \text { ) }\end{array}$ \\
\hline $0.8+1.5-\mathrm{N}$ & 3.47 & 86.8 & 2.63 & 65.8 \\
\hline $1.5+0.8-P$ & 4.34 & 108.5 & 3.76 & 94 \\
\hline
\end{tabular}

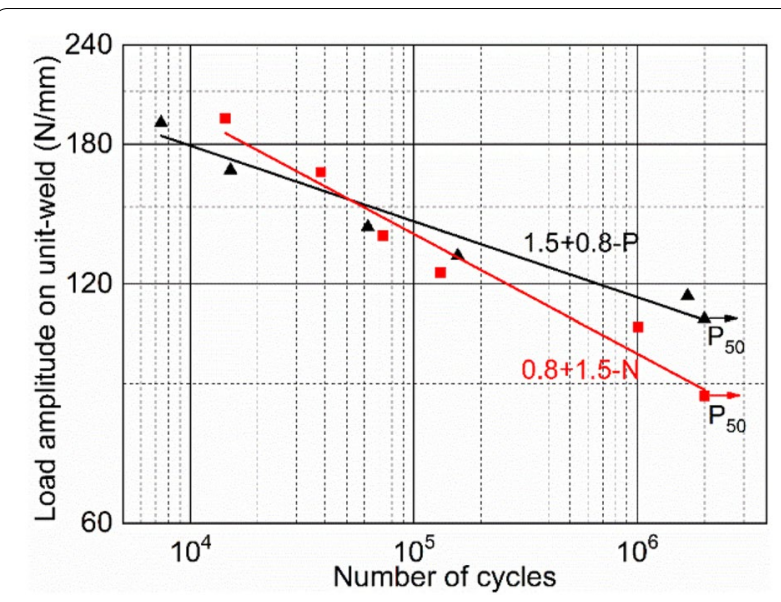

Figure $6 \mathrm{~S}-\mathrm{N}$ curves of penetration 1.5+0.8-P and non-penetration $0.8+1.5-\mathrm{N}$ specimens 

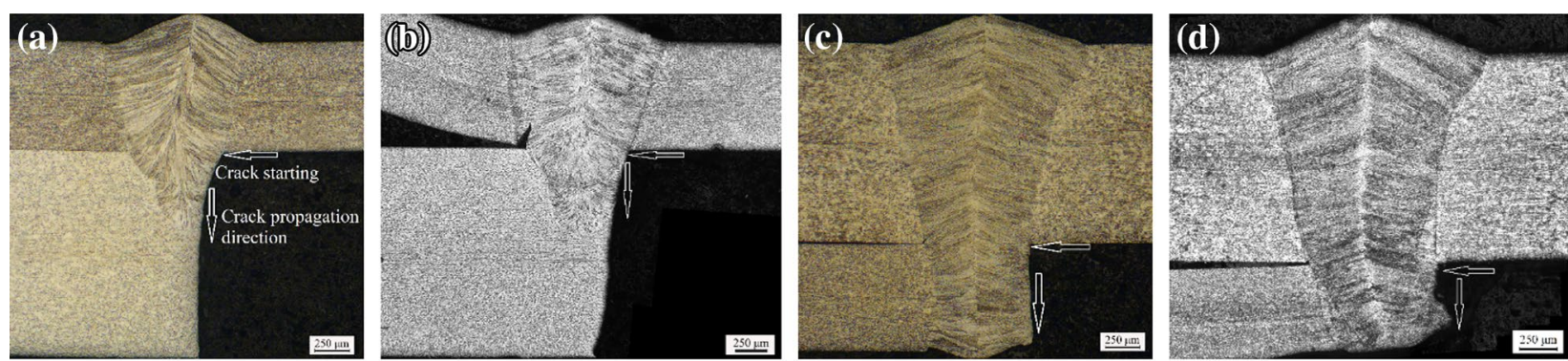

Figure 7 Cross-sectional micrographs of fatigue failure specimens: $\mathbf{a} 0.8+1.5-\mathrm{N}$ failed at $1.01 \times 10^{6} \mathrm{cycle}, \mathbf{b} 0.8+1.5-\mathrm{N}$ failed $3.84 \times 10^{4}, \mathbf{c} 1.5+0.8-\mathrm{P}$ failed at $1.68 \times 10^{6}$ cycle, d 1.5+0.8-P failed at $1.51 \times 10^{4}$ cycle
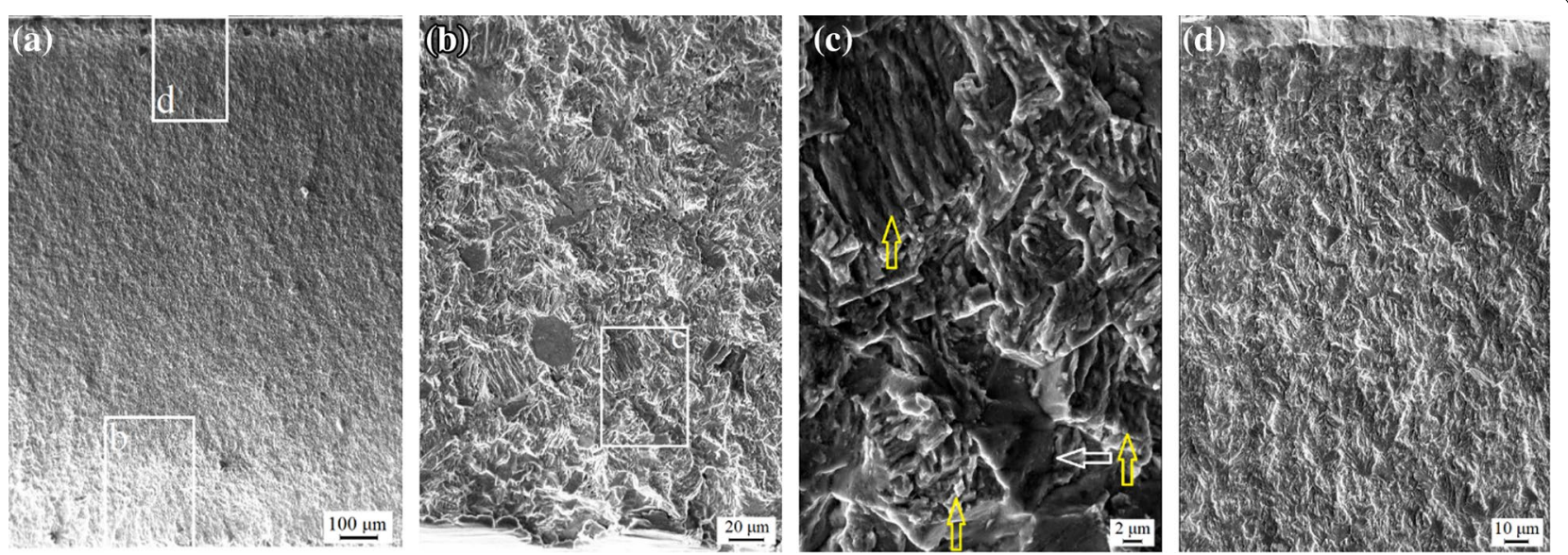

Figure 8 Fracture morphology of $1.5 \mathrm{~mm}$ fatigue fracture plate in $0.8+1.5-\mathrm{N}$ specimen failed at $1.01 \times 10^{6} \mathrm{cycle:}$ a overall view of fracture surface, $\mathbf{b}$ crack initial extension region near lap interface, $\mathbf{c}$ transgranular and intergranular fractures of weld grains at fusion boundary, $\mathbf{d}$ ending region of crack growth

the top. Figure 8(a) shows the overall view of the fracture surface, and no plastic ribs are visible in the initial crack propagation region at the bottom. Figures 8 (b) and (c) are fractographs of the initial crack propagation region near the lap interface, and the transgranular and intergranular fractures of the weld columnar grains perpendicular to the fusion line can be observed as shown by the yellow and white arrows, respectively, which indicates that the welding fusion boundary near the lap interface was the initial cracking site. Figure 8(d) shows a fractograph of the final rapid crack propagation region close to the non-penetrated surface, which shows that there are small cleavage fractures but no plastic dimples, even in the ending fatigue fracture of the cold-rolled plate. Figure 9 shows fatigue fractographs of the $0.8 \mathrm{~mm}$ plate in a 1.5+0.8-P specimen fractured at a low stress amplitude (with $1.68 \times 10^{6}$ cycle life). Figure 9(a) shows the overall view of the fracture surface and there are long plastic ribs in the initial crack growth region at the bottom. The transgranular and intergranular fractures of the weld columnar grains are also observed in the magnified images of the initial crack extension region, as shown in Figures 9(b) and (c), which proves that the welding fusion boundary was the initial cracking area. The diameter of the weld columnar grains shown in the fatigue fractographs was less than $20 \mu \mathrm{m}$. The fractograph of the crack propagation region in the middle of the cold-rolled plate is shown in Figure 9(d), and there are plastic ribs without smooth cleavage fractures.

\subsection{Stress Simulation Analysis}

Stress simulation analysis of the $0.8+1.5-\mathrm{N}$ and $1.5+0.8$-P laser welded joints under the load of mean fatigue limits $P_{50}$ was performed using Abaqus software to obtain their fatigue resistance stresses. Based on the specimen sizes shown in Figure 1, finite element models of the two laser welded specimens were developed, as shown in Figure 10. The mesh size near the weld at the lap interface was $0.1 \times 0.1 \times 0.5 \mathrm{~mm}^{3}$ in the $X-Y-Z$ coordinates, and the element type was C3D8R. Young's 

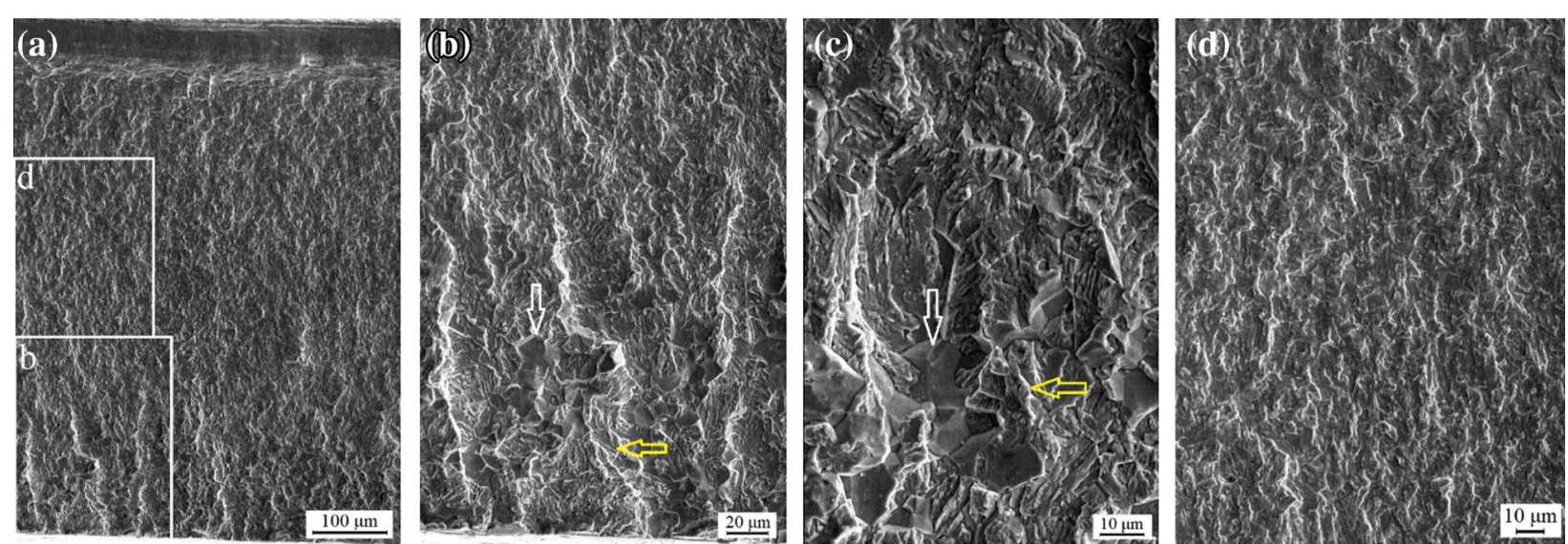

Figure 9 Fracture morphology of $0.8 \mathrm{~mm}$ fatigue fracture plate in $1.5+0.8-\mathrm{P}$ specimen failed at $1.68 \times 10^{6} \mathrm{cycle:}$ a overall view of fracture surface near lap interface, $\mathbf{b}$ transgranular and intergranular fractures of weld grains in crack initiation region at fusion boundary, $\mathbf{c}$ slow crack growth area, $\mathbf{d}$ rapid crack growth area

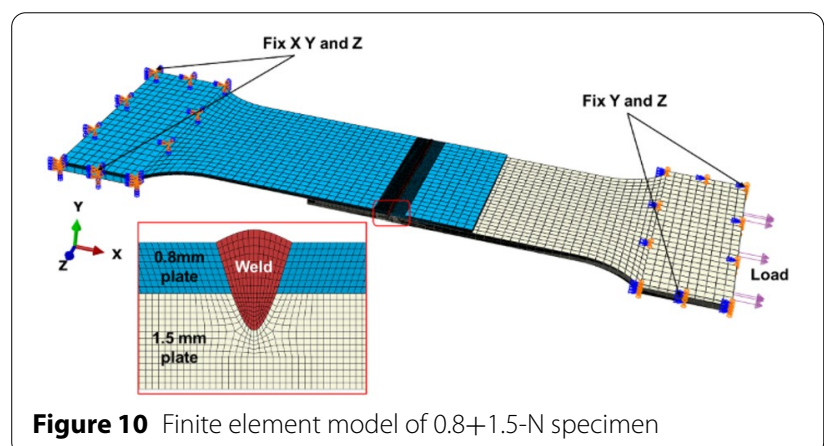

modulus and Poisson's ratio were $206 \mathrm{GPa}$ and 0.3 , and the yield strengths of the weld bead and base metal were $350 \mathrm{MPa}$ and $400 \mathrm{MPa}$, respectively. As shown in Figure 10, the left side of the specimen was fixed in the $X, Y$ and $Z$ directions, the fatigue load was applied in the right
$X$ direction, and the $Y$ and $Z$ directions were fixed. The calculated stress distributions of the upper and lower lap plates in the two joints are shown in Figure 11, and the maximum Mises stresses are listed in Table 4.

Figure 11 shows that the maximum Mises stress of the lap welded plates was located near the welding fusion line at the lap interface, and the stress decreased with increase in plate thickness. Under the load of the mean fatigue limit, the maximum stress of the non-penetration $0.8+1.5-\mathrm{N}$ joint was lower than the yield strength of the base metal, and the welded joint was completely linearly elastic. However, the maximum stress in the $0.8 \mathrm{~mm}$ plate of the penetration $1.5+0.8-\mathrm{P}$ specimen was very close to the yield strength, and strain analysis proved that there was a small yielded area in the lower plate near the weld at lap interface, as shown in Figure 12.

The maximum stress position of the penetration $1.5+0.8-\mathrm{P}$ joint was coincided with the initiation site
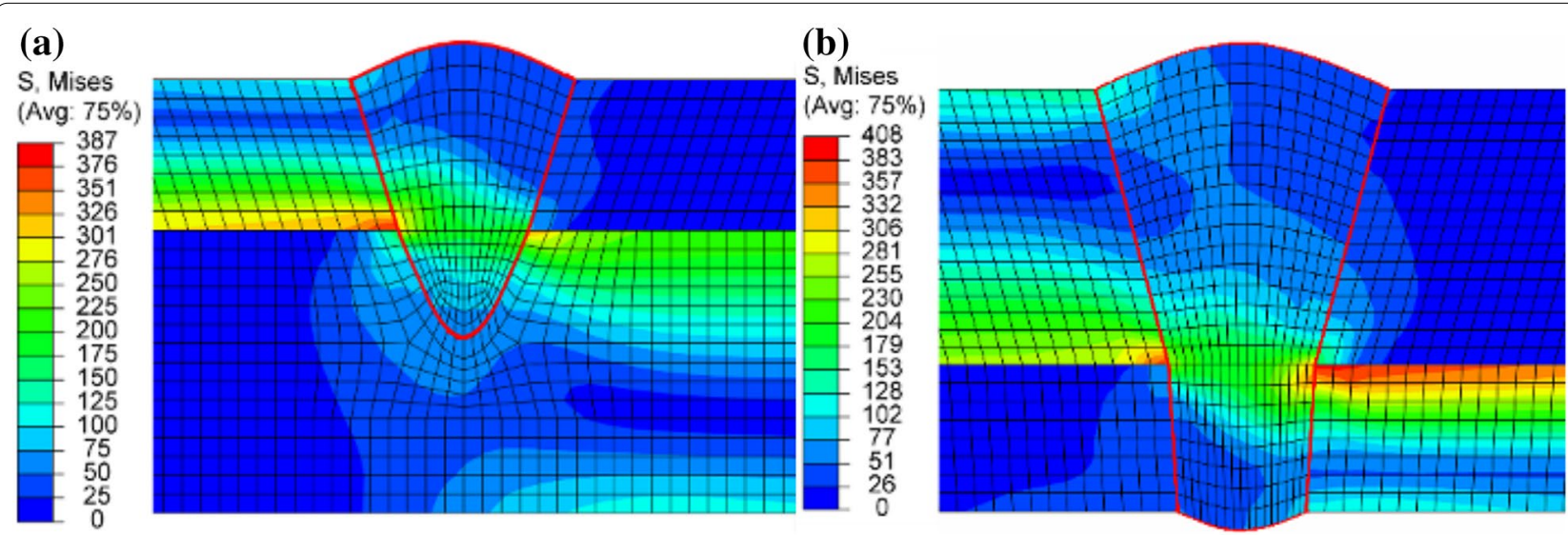

Figure 11 Mises stress in cross-section of a $0.8+1.5-\mathrm{N}, \mathbf{b} 1.5+0.8-\mathrm{P}$ joints 
Table 4 Maximum Mises stress of the upper and lower plates under loads of mean fatigue limit $P_{50}$

\begin{tabular}{llll}
\hline Specimen & $P_{50}(\mathrm{kN})$ & Upper plate $\sigma_{\text {Mises }}$ & $\begin{array}{l}\text { Lower } \\
\text { plate } \\
\sigma_{\text {Mises }}\end{array}$ \\
\hline $0.8+1.5-\mathrm{N}$ & 3.47 & 387 & 326 \\
$1.5+0.8-\mathrm{P}$ & 4.34 & 354 & 408 \\
\hline
\end{tabular}

of the primary fatigue crack in the $0.8 \mathrm{~mm}$ sheet. However, the initiation site of the primary fatigue crack in the non-penetration $0.8+1.5-\mathrm{N}$ joint was located in the non-penetration $1.5 \mathrm{~mm}$ plate, rather than the maximum stress position, and its stress was lower $61 \mathrm{MPa}$ than the maximum stress, which may be related to its larger welding residual stress.

\subsection{Analysis and Discussion}

The fracture location is the result of competition between the local stress and fatigue resistance in welded joints, and the fatigue strength of welded joints depends on the fatigue resistance of their fracture regions [17-20]. The fatigue fracture of the penetration and non-penetration joints was initiated at the welding fusion boundary on the lap interface of the lower lap plate, which indicated that the fusion boundary of the two laser welded joints had relatively low fatigue resistance and high stress. However, the fatigue resistance of the penetration and non-penetration joints made of the same lap plates was different. Owing to the lower local notch stress in the fractured plate, the fatigue resistance of the $0.8+1.5-\mathrm{N}$ joint to high stress amplitudes was higher than that of the $1.5+0.8-\mathrm{P}$ joint. However, the resistance of the two joints to low stress amplitudes was the opposite, the $1.5+0.8-\mathrm{P}$ joint with the higher local stress in the fractured plate showed the higher fatigue strength than the $0.8+1.5-\mathrm{N}$ joint with the lower local stress, which may be due to residual stress.

The welding heat input is asymmetrical in the thickness of the non-penetration plate, where the solidification and phase transformation of the weld bead are not synchronized with the cooling contraction of the partial non-penetrated plate, and the constraint of free expansion and contraction of the weld bead in the non-penetration plate is greater than that of the penetration plate. Therefore, the residual stress near the weld fusion line of the non-penetration plate is much higher than that of the penetration plate [21-23].

The influence of residual stress on fatigue performance depends on the applied stress ratio [24, 25]. The initial residual stress tends to relax during the cyclic loading process, and the extent of relaxation depends on the plastic strain caused by the increasing applied load, and if the applied tensile mean stress is sufficiently high, the effect of the residual tensile stresses generally vanishes [24-29]. In the elastic zone of low applied mean stress, the combination of residual tensile stress and applied load increases the mean stress and makes the welded joint seem to work under higher loads, thereby reducing the highcycle fatigue resistance, whereas the residual stress does not contribute to the plastic collapse at crack tips [2426], which coincides with the fatigue fractograph of the high-cycle failure $0.8-1.5-\mathrm{N}$ joint without plastic region. Therefore, the low stress amplitude fracture of the nonpenetration plate in the $0.8+1.5-\mathrm{N}$ joint was the result of the combination of local notch stress and residual stress, and the fracture of the penetration plate in the $1.5+0.8-\mathrm{P}$ joint was mainly caused by the local notch stress, which resulted in a reduction of $61 \mathrm{MPa}$ in the fatigue resistance stress of the non-penetration plate. In addition, because both the stress intensity factor and the crack propagation rate of the cracking thinner plate are higher than those of

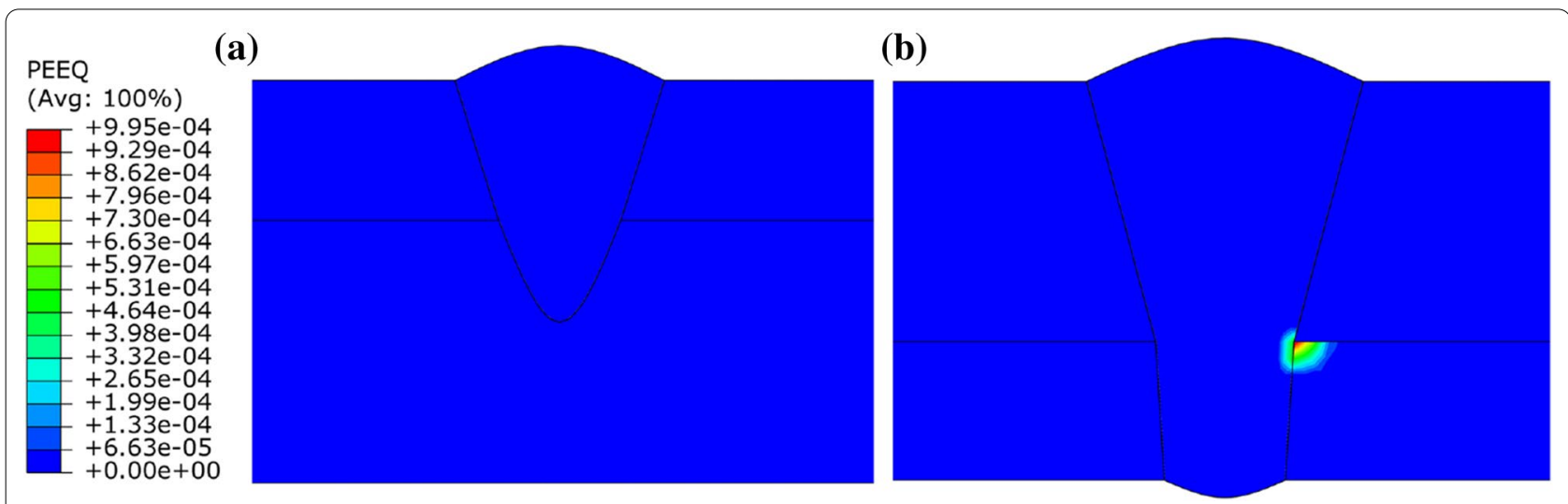

Figure 12 Equivalent plastic strain (PEEQ) in cross-section of a $0.8+1.5-\mathrm{N}, \mathbf{b} 1.5+0.8-\mathrm{P}$ joints 
the thicker plate and the propagation life accounts for a larger ratio in the short life of the fatigue specimen, the fatigue resistance of the $1.5+0.8-\mathrm{P}$ weldment to the high stress amplitude was lower than that of the $0.8+1.5-\mathrm{N}$. The fatigue resistance stress at the primary crack initiated position of the penetration and non-penetration laser welded joints calculated based on their mean fatigue limits can be used as reference stress for the fatigue design of laser welded structures.

\section{Conclusions}

(1) The microstructure of the weld was composed of austenite substrate and $\delta$ ferrite dendrites solidified with primary ferrite, which has a good thermal cracking resistance. The hardness of the weld beads was close to that of the HAZ but lower than that of the plates. The tensile curves of two specimens exhibited coincidence and the maximum load of the 1.5+0.8-P joint was higher owing to its wider interfacial weld bead.

(2) The non-penetration $0.8+1.5-\mathrm{N}$ joint exhibited slightly higher fatigue resistance at high stress amplitudes, whereas the penetration 1.5+0.8-P joint showed much higher fatigue resistance at low stress amplitudes. The mean fatigue limits of the $0.8+1.5-\mathrm{N}$ and $1.5+0.8-\mathrm{P}$ joints were the normalized loads of $86.8 \mathrm{~N} / \mathrm{mm}$ and $108.5 \mathrm{~N} / \mathrm{mm}$, respectively.

(3) The primary fatigue crack of both $1.5+0.8-\mathrm{P}$ and $0.8+1.5-\mathrm{N}$ joints initiated at the welding fusion boundary on the lap interface of the lower lap plates and extended through the thickness. There were long plastic ribs in the fracture of the penetration plate, but not in the non-penetration plate. The difference in fatigue resistance between the penetration and non-penetration joints was mainly due to the higher welding residual stress in the non-penetration joint caused by the asymmetrical heating in the thickness of the lower lap plate.

(4) The fatigue resistance stresses at the primary crack initiated position of the penetration and non-penetration laser welded joints calculated based on the mean fatigue limits are $408 \mathrm{MPa}$ and $326 \mathrm{MPa}$, respectively, which can be used as reference stress for the fatigue design of laser welded structures.

\section{Acknowledgements}

The authors sincerely thank CSR Qingdao Sifang Corporation for their help with the welding process.

\section{Authors' Contributions}

WL was in charge of the whole trial; $X G$ wrote the manuscript; $X L$ and $H S$ assisted with sampling and laboratory analyses; ZS guided the experiments. All authors read and approved the final manuscript.

\section{Authors' Information}

Xiangzhong Guo, born in 1992, is currently a PhD candidate at School of Mechanical, Electronic and Control Engineering, Beijing Jiaotong University, China. His research interests include vehicle structure strength and fatigue life prediction.

Wei Liu, Doctor of Engineering, Professor, mainly engaged in laser rapid forming technology of vehicle components and their service performances.

Xiqing Li, born in 1996, is currently a PhD candidate at School of Mechanical, Electronic and Control Engineering, Beijing Jiaotong University, China.

Haowen Shi, born in 1997, is currently a master candidate at School of Mechanical, Electronic and Control Engineering, Beijing Jiaotong University, China.

Zhikun Song, Doctor of Engineering, Associate Professor, mainly engaged in vehicle structure strength and fatigue reliability.

\section{Funding}

Supported by Scientific Research and Development Projects of China Railway Corporation (Grant No. 2017J011-C).

\section{Competing Interests}

The authors declare no competing financial interests.

Received: 12 July 2020 Revised: 6 February 2021 Accepted: 26 March 2021

Published online: 13 April 2021

\section{References}

[1] W Jaxa-Rozen. Cold-worked austenitic stainless steels in passenger railcars and in other applications. Thin-Walled Structures, 2014, 83: 190-199.

[2] W Liu, R J Wang, J L Han, et al. Microstructure and mechanical performance of resistance spot-welded cold-rolled high strength austenitic stainless steel. Journal of Materials Processing Technology, 2010, 210: 1956-1961.

[3] Y Qin, S Xiao, L Lu, et al. Structural stress-fatigue life curve improvement of spot welding based on quasi-newton method. Chinese Journal of Mechanical Engineering, 2020, 33: 36, https://doi.org/10.1186/ s10033-020-00453-3.

[4] X Z Guo, W Liu, X Q Li, et al. A new approach to improve ductility of nonpenetrating laser welded lap joints of cold-rolled $301 \mathrm{LN}$ stainless steel. Welding in the world, 2021, 65: 87-93.

[5] K M Hong, Y C Shin. Prospects of laser welding technology in the automotive industry: A review. Journal of Materials Processing Technology, 2017, 245: 46-69

[6] C Cerrone, F Chiti, M Sacchi, et al. Application of laser welding to stainless steel light rail vehicle. Welding in the World, 2008, 52: 7-8.

[7] R A Sindhu, M K Park, S J Lee, et al. Effects of residual stresses on the static and fatigue strength of laser-welded lap joints with different welding speeds. International Journal of Automotive Technology, 2010, 11: 857-863.

[8] TTerasaki, T Kitamura, T Sobue. Fatigue strength of laser welded lap joints. Welding International, 2002, 16(4): 293-298.

[9] K Asim, K Sripichai, J Pan. Fatigue behavior of laser welds in lap-shear specimens of high strength low alloy steel sheets. International Journal of Fatigue, 2014, 61: 283-296.

[10] M Ono, M Kabasawa, M Omura. Static and fatigue strength of laserwelded lap joints in thin steel sheet. Welding International, 1997, 11(6): 462-467.

[11] A Y Kaitanov, A Ozersky, A M Zabelin, et al. Static and fatigue strengths of laser-welded overlap joints with controlled penetration. In Seventh International Conference on Laser and Laser-Information Technologies, 2002, 116-126. 
[12] S K Cho, Y S Yang, K J Son, et al. Fatigue strength in laser welding of the lap joint. Finite Elements in Analysis and Design, 2004, 40(9-10): 1059-1070.

[13] K Sripichai, K Asim, J Pan. Stress intensity factor solutions for estimation of fatigue lives of laser welds in lap-shear specimens. Engineering Fracture Mechanics, 2011, 78(7): 1424-1440.

[14] G Marulo, J Baumgartner, F Frendo. Fatigue strength assessment of laser welded thin-walled joints made of mild and high strength steel. International Journal of Fatigue, 2017, 96: 142-151.

[15] Z T Gao. Fatigue applied statistics. Beijing: National Defense Industry Press, 1986. (in Chinese)

[16] D Radaj. Fatigue strength of welded structures. Beijing: Publication of Mechanical Industry, 1994. (in Chinese)

[17] P Gallo, M Guglielmo, J Romanoff, et al. Influence of crack tip plasticity on fatigue behaviour of laser stake-welded T-joints made of thin plates. International Journal of Mechanical Sciences, 2018, 136: 112-123.

[18] S Liu, A Kouadri-Henni, A Gavrus. Numerical simulation and experimental investigation on the residual stresses in a laser beam welded dual phase DP600 steel plate: Thermomechanical material plasticity model. International Journal of Mechanical Sciences, 2017, 122: 235-243.

[19] J W Sowards, E A Pfeif, M J Connolly, et al. Low-cycle fatigue behavior of fiber-laser welded, corrosion-resistant, high-strength low alloy sheet steel. Material Design, 2017, 121: 393-405.

[20] S Kumar, A Kundu, K A Venkata, et al. Residual stresses in laser welded ASTMA387 Grade 91 steel plates. Materials Science and Engineering: A, 2013, 575: 160-168.

[21] L Zhang, J Z Lu, KY Luo, et al. Residual stress, micro-hardness and tensile properties of ANSI304 stainless steel thick sheet by fiber laser welding. Materials Science and Engineering: A, 2013, 561: 136.
[22] P D Babu, P Gouthaman, P Marimuthu. Effect of heat sink and cooling mediums on ferrite austenite ratio and distortion in laser welding of duplex stainless steel 2205. Chinese Journal of Mechanical Engineering, 2019, 32: 50, https://doi.org/10.1186/s10033-019-0363-5.

[23] J Lin, N Ma, Y Lei, et al. Measurement of residual stress in arc welded lap joints by cosa X-ray diffraction method. Journal of Materials Processing Technology, 2017, 243: 387-394.

[24] J Hensel, T Nitschke-Pagel, D Tchoffo Ngoula, et al. Welding residual stresses as needed for the prediction of fatigue crack propagation and fatigue strength. Engineering Fracture Mechanics, 2018, 198: 123-141.

[25] WY Zhang, W C Jiang, X Zhao, et al. Fatigue life of a dissimilar welded joint considering the weld residual stress: Experimental and finite element simulation. International Journal of Fatigue, 2018, 109: 182-190.

[26] HCYıldırım. Recent results on fatigue strength improvement of highstrength steel welded joints. International Journal of Fatigue, 2017, 101: 408-420.

[27] E Harati, L Karlsson, L E Svensson, et al. The relative effects of residual stresses and weld toe geometry on fatigue life of weldments. International Journal of Fatigue, 2015, 77: 160-165.

[28] F Shen, B Zhao, L Li, et al. Fatigue damage evolution and lifetime prediction of welded joints with the consideration of residual stresses and porosity. International Journal of Fatigue, 2017, 103: 272-279.

[29] D Tchoffo Ngoula, H Th Beier, M Vormwald. Fatigue crack growth in cruciform welded joints: Influence of residual stresses and of the weld toe geometry. International Journal of Fatigue, 2017, 101: 253-262.

\section{Submit your manuscript to a SpringerOpen ${ }^{\circ}$ journal and benefit from:}

- Convenient online submission

- Rigorous peer review

- Open access: articles freely available online

- High visibility within the field

- Retaining the copyright to your article

Submit your next manuscript at $\mathbf{s p r i n g e r o p e n . c o m ~}$ 